\title{
Children experiencing sadness: Coping strategies and attachment relationships
}

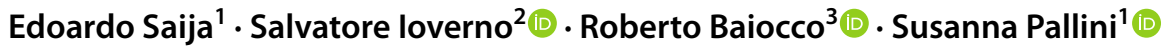 \\ Accepted: 20 January 2022 \\ (c) The Author(s), under exclusive licence to Springer Science+Business Media, LLC, part of Springer Nature 2022
}

\begin{abstract}
This study aimed to explore the events which are sources of sadness for children, and their coping strategies for overcoming their sadness according to their attachment security. We expected that distinct clusters would emerge, with securely attached children more likely showing constructive and successful coping strategies than insecurely attached children. Middle-class children $(N=191)$ aged $7-11$ years old from four private elementary schools were asked to talk about a sad event they experienced using open-ended questions from the Sadness Interview. The answers were coded into different categories of sad events and associated coping strategies. Finally, children were assessed on their security attachment using the Security Scale. Cluster analyses identified a four-cluster solution. Children in the Clusters 1 and 2 were characterized by a perceived successful constructive coping strategy while describing minor events (in the first Cluster), and very painful events (in the second). Furthermore, in the third Cluster children overcame sad events using a perceived successful disengagement coping strategy, whereas children in the fourth Cluster are characterized by perceived unresolved sadness. ANCOVA testing showed that children in the first cluster had significantly higher attachment security compared to Clusters 3 and 4 , which did not significantly differ from each other. The study of sadness in children may be particularly informative for clinicians and educators for understanding and supporting children's strategies of sadness management while considering the influence of their attachment relationships on their ability to cope with sadness.
\end{abstract}

Keywords Coping strategies $\cdot$ Emotion regulation $\cdot$ Sadness $\cdot$ Attachment security $\cdot$ Middle childhood

\section{Introduction}

The examination of children's ability to manage sadness is a largely unexplored area. Indeed, compared to other negative emotionalities such as anger or fear, few studies have addressed this topic (Song et al., 2018). This gap in previous research is explained in part by ethical concerns related to studying sadness in children, especially considering the general tendency to consider sadness as a disorder (Lomas, 2018). Often, studies overlook the positive values of the

Salvatore Ioverno

salvatore.ioverno@ugent.be

1 Department of Education, Roma Tre University, Via di Castro Pretorio n. 20, Rome, Italy

2 Department of Sociology, Ghent University, Korte Meer 5, Ghent, Belgium

3 Department of Developmental and Social Psychology, Sapienza University of Rome, Via dei Marsi n.78, Rome, Italy experience of sadness in children and its inherent value of fostering psychological development (i.e., moral sensibility) and prosocial behaviours (Lomas, 2018; Song et al., 2018). Thus, distinguishing children's sadness from pathological depression would be particularly informative for clinicians and educators in understanding the strategies which children use for managing sadness (Zeman et al., 2001).

The concept of emotion regulation is critically relevant when exploring the processing of sadness. Emotion regulation refers to the "extrinsic and intrinsic processes responsible for monitoring, evaluating, and modifying emotional reactions, especially their intensive and temporal features, to accomplish one's goals" (Thompson, 1994, p. 27). Abraham and Kerns (2013) and Contreras et al. (2000) considered the strategies of coping as the main outcome of the emotion regulation process. However, as Compas et al. (2017) observed, coping and emotion regulation are two distinct constructs: Emotion regulation regards the active efforts to regulate emotions (either positive or negative, and whether or not the emotion arises in response to a stressor), whereas the 
concept of coping regards the active efforts to regulate external and/or internal stressors (Lazarus \& Folkman, 1984). Overall, the coping and emotion regulation constructs can overlap resulting in an "emotion regulation coping" mechanism - that is, the ability to cope effectively with negative emotions by controlling emotional arousal to prevent undesirable consequences (Zeman et al., 2001).

Consistently with prior research (Abraham \& Kerns, 2013; Contreras \& Kerns, 2000; Eisenberg et al., 1996; Laible \& Thompson, 2007), in the present paper, we use the term constructive coping strategy to define specific individuals' responses to stress such as problem-solving, support-seeking, and emotion expression. Specifically, the term constructive defines those strategies which, in the face of the stressors, cause people to feel that something constructive can be done to cope with the stress (Carver et al., 1989). Moreover, the term constructive coping is also used in the theory of attachment for indicating those responses which contribute to regulating emotions (see also Contreras \& Kerns, 2000; Laible \& Thompson, 2007).

\section{Sadness Regulation and Associated Variables}

Several factors are involved in sadness regulation among children: the characteristics of episodes triggering sadness, children's attachment security, and the regulation coping strategies to address sadness (see Quiñones-Camacho \& Davis, 2019; Zimmer-Gembeck et al., 2017). In the field of attachment theory and research, the relationship with the caregiver has been identified as the foundation for the emergence and development of children's capacity for emotion regulation and coping with stress (Yunger et al., 2005; Zimmer-Gembeck et al., 2017). Indeed, the definition of attachment security refers to the perception of the caregivers as available, sensitive, and able to regulate their child's emotions and the competent use of the caregivers as a base for exploration. These are critical aspects on which confidence and the ability to cope with stressful events and negative emotions are grounded (see Bowlby, 1988; Waters \& Cummings, 2000; Zimmer-Gembeck et al., 2017).

Thus, the role of attachment relationships has been well-documented as a powerful source of emotion regulation (see Brumariu, 2015; Zimmer-Gembeck et al., 2017; Cooke et al., 2019 for a review). In a secure attachment relationship, parents in the first years sensitively help their children to understand and to regulate their emotions, fostering a consequent ability of self-regulation (e.g. Cassidy, 1994). A recent study by Deichmann and Ahnert (2021) used the Experimental Frustration Procedures to examine toddlers' coping strategies and parents' supportive behaviours and found that children in a secure attachment relationship likely experienced frustration for a shorter period compared to children in an insecure attachment relationship.
By experiencing external regulation, children progressively develop internal working models (IWMs) of attachment relationships characterized by memories, expectations, and trust in caregivers' support and comfort every time they experience feelings of fear, upset, or sadness. On one hand, attachment IWMs contribute to the development of general trust in the value of the interpersonal relationships in times of emotional difficulty, and, thus, foster the expression of emotion and the request for help (Cassidy, 1994). On the other hand, caregivers' emotion regulation constitutes a scaffolding for the development of the autonomous ability of emotional self-regulation, fostering self-efficacy, the agency to cope with difficulty, and consequently, resilience against it. Taken together, securely attached children compared to insecurely attached, are both more self-confident and active to regulate emotions and use social support coping strategies (see Cooke et al., 2019, for a meta-analytic review). In line with these findings, Ştefan et al. (2017)'s study of the effects of attachment status on pre-schoolers' awareness of anger, sadness, and fear regulation strategies, revealed that the insecure-avoidant pre-schoolers were significantly less likely than securely attached ones to generate both comforting and self-regulatory strategies. In middle childhood, the study of Contreras et al. (2000) evidenced that secure attachment was associated with greater use of constructive coping strategies; the study of Kerns et al. (2007) found an association between secure attachment and high levels of positive mood, constructive coping, and emotion regulation. Finally, Psouni and Apetroaia (2014) found that attachment security predicted the capacity to respond to distress with constructive coping strategies which may involve seeking support and comfort from others or engaging in a comforting activity such as play. Indeed, play may be considered as an active coping strategy for children because of its value for events processing and emotion regulation (Polan \& Hofer, 2016).

\section{Top-Down, or Bottom-Up Approach for Studying Coping Strategies}

The selection of the instruments across studies was largely influenced by whether scholars used a top-down or a bottom-up approach to investigate this topic. In a top-down approach, children are presented with predetermined scenarios eliciting negative emotions and asked to identify the most effective coping strategy from a predetermined set. To examine children's inhibition, dysregulated expression, and coping with a general experience of sadness, these studies used standardized measures and structured stimuli such as, for example, the Children's Sadness Management Scale (Webb et al., 2012), or illustrated storyboards depicting situations that evoke anger or sadness (e.g., Waters \& Thompson, 2014). In particular, Abraham and Kerns (2013) asked 8-12-year-old girls' mothers to report their children's 
coping strategies when upset, according to the coping strategies classification of Eisenberg et al. (1996); the authors considered problem-solving and support seeking as constructive coping strategies; Waters and Thompson (2014) asked 6-9-year-old children to rate the efficacy of a series of predetermined emotion regulation strategies for addressing anger and sadness in situations as displayed by illustrated storyboards. Results showed that children considered problem-solving as more effective for anger, whereas seeking adult support and venting emotion were considered more effective for sadness.

In studies using a bottom-up approach, children are generally asked an open-ended question about which strategies they would use during a problematic situation. By not using a predetermined set of coping strategies or prompts for problematic situations, this approach allows for the identification of more individual strategies. A meta-analytical review on coping and emotion regulation (Compas et al., 2017) showed that this approach is limited in identifying alternative coping strategies and hierarchical structures of such strategies. Nevertheless, Quiñones-Camacho and Davis (2019) were able to use a bottom-up approach to connect different strategies with specific events that the children considered relevant. Specifically, in examining the links among emotional self-regulatory processes, stress, and anxiety symptoms in 6-11-year-old children, the authors derived an index of nine environmental stressors and categorized children's emotion regulation strategy awareness from an interview about their experiences of sadness, fear, and anger. Their coding scheme was data-derived and encompassed categories such as problem-solving, changing thoughts, changing goals, changing physiology, social support, religious activity, and acceptance. In another study using a bottom-up strategy in an adult sample, Quiñones-Camacho and Davis (2020) showed that the effectiveness of an emotion regulation strategy depends on the emotional context in which it is used (e.g. sadness vs. anger). Their findings highlight the importance of applying a post hoc categorization of problematic situations described by participants rather than using an a priori categorization based on a predetermined set of problematic situations. Another example of a post hoc categorization was applied in Steyn and Moen's study (2019) using children's drawings about their experiences of sadness. The authors found two distinctive themes: bullying-based violence, and experiences of loss.

Considering all these methodological approaches, we believe that using a bottom-up approach starting from children's autobiographical experiences would be a valuable strategy to understand how children use contextual information during real-life instances of emotional experiences. Indeed, the extent to which specific coping strategies are considered constructive among children may depend on the type of event and the perceived control over it (Skinner \&
Wellborn, 1994). These characteristics are particularly relevant considering that children, especially in middle childhood, use contextual information (i.e., who is around) to inform their decisions about regulatory choices (Abraham \& Kerns, 2013; Zeman \& Garber, 1996; Zeman \& Shipman, 1997). For example, a caregiver's support may be less likely to be requested in some cases, especially when the caregiver is the source of frustrations. In these situations, children may opt for other coping strategies such as suppressing their emotional experience to avoid negative consequences (Zeman \& Garber, 1996), or relying on peer support (Marsac et al., 2014) or problem-solving coping strategies (Abraham \& Kerns, 2013). However, regardless of the contexts, children's relationship with their caregivers serves as the context in which regulatory choices develop and coping strategies are learned (Abraham \& Kerns, 2013).

\section{The Present Study}

This study aimed to use a bottom-up approach to explore how children with different attachment security levels address events perceived as sad. The bottom-up approach was considered the most appropriate strategy for two main reasons: 1) There is limited knowledge in research about the links between sad events, attachment security, and coping strategies among children; 2) contextual factors are crucial in defining the perceived sadness of the events and the constructiveness of the coping strategies among children (Skinner \& Wellborn, 1994). Thus, for the present study, progressing from individual experiences to build a view of the whole and piecing information together until a larger picture is formed was preferred over an approach using an already formulated system or knowledge to understand individual cases.

This research comes at a time when all children have faced an unprecedented worldwide public health event that caused disruptions to their daily life, the COVID-19 pandemic. Anxiety, depression, disturbances in sleep, appetite, and impairment in social interactions are the most common consequences associated with the impact of COVID-19 (Meherali et al., 2021). According to a recent cross-national study, the most common children's responses to this crisis were accepting the situation, being involved in social activities, ignoring the problem, highlighting the advantages of being at home, seeking comfort from others (Orgilés et al., 2021). A further understanding of how often the COVID19 is evoked among children as a major sad event and how children respond to this crisis in light of their attachment style remain of great importance.

Our main study hypothesis was that the type of evoked sad event, the coping strategies, and the successful overcoming of the emotions of sadness would vary meaningfully among children, and that said variability would have bearing 
on the children's attachment security. Cluster analysis was used to test the primary study hypothesis of meaningful within-group variability. We expected that several distinct clusters would emerge, including groups of children who evoke similar sad episodes and use similar strategies to solve them. Previous research has analyzed coping strategies when dealing with given situations using cluster analytic methods, all of them using given stimuli and analyzing a range of negative emotions. In particular, among early adolescents, Zimmer-Gembeck et al. (2013) identified clusters of emotional reactions to different stressors and found that the quality of coping strategies depends on the intensity of the emotions and the sources of stress. Chalmers et al. (2011) interviewed 4-year old children about their reactions when dealing with seven age-appropriate challenging situations and were able to cluster the coping strategies into productive and nonproductive coping styles. Finally, Han and Shaffer (2013) identified two clusters of emotion regulation styles among children aged 8 to 11 , externalizing coping styles and internalizing coping styles. Contrary to previous studies, our cluster analysis focused specifically on the sadness in middle childhood children and identified patterns of coping for dealing with sad events not proposed by the interviewer, but narrated by the children, and related coping strategies to their perceived success in overcoming sadness. Given the exploratory nature of this classification, we did not impose an a priori classification scheme on the data. However, based on the results from prior literature, we could expect some attachment security differences across clusters. Specifically, we expected that children with high levels of security attachment would be more likely to fall into the clusters of children who evoked sad events that had been resolved using constructive coping strategies. Moreover, we did not have a clear prediction regarding differences in the content of the episodes evoked according to the attachment security, even if we speculated that their proneness to exploration and attentive flexibility (Pallini et al., 2019) would more likely cause secure children to evoke sad episodes related to the external world and not only to their inner world, than insecure children. Conversely, children with low levels of attachment security, not having the ability to regulate their negative arousal (Cassidy, 1994), would be more likely to evoke unresolved sad events and to respond with disengagement or no reaction.

\section{Method}

\section{Participants}

Participants were 191 children aged $7-11$ years old $(M=8.86 ; S D=0.97 ; 57.1 \%$ girls $)$. Children were recruited from four private elementary schools serving primarily middle-class residents, in a large city, in the centre of Italy. All children were born in Italy. The participants were recruited through second to fifth-grade elementary schools. University of Rome Tre Ethics Committee approval was granted and participants' information has been de-identified by making sure that all personal identifiers, both direct and indirect, that may lead to a child being identified were removed during data processing.

\section{Measures}

Sadness Interview Following the Quiñones-Camacho and Davis (2019) method, children were interviewed about events that made them feel sad. The experimenter said: "Let's think about a time recently when you felt very sad and all of the little details you can remember about it. Would you like to describe it in writing?" Children were given a minute to think and then the children described the event in writing. Afterward, the experimenter asked the following questions: 1) "What did you do to make yourself feel less sad?" 2) "Did you succeed in overcoming the sadness?"

Responses to open and closed questions were transcribed on a spreadsheet. The answers to the first and second questions were coded by trained research assistants into different categories (more details are provided below). The answers to the third question were dichotomized $(0=N o ; 1=Y e s)$. The questions were age-appropriate and structured in a way that 7-year-old children could easily provide basic information about the episode that made them sad and how they responded to the sad event.

Security Scale To measure attachment security, the children completed the Security Scale (Kerns et al., 1996), a selfreport questionnaire that assesses children's perceptions of communication with, and accessibility and responsiveness of the mother (15 items) and the father (15 items). Kerns et al. (1996) have created this scale using the Harter scale (1982) "some kids/other kids" format, in which children are presented with two possible statements and are asked to indicate which group of kids they are most similar to. An example of an item is: "some kids go to their mom when they are upset, but other kids do not go to their mom when they are upset." Children choose the sentence which they feel is most like them and then mark whether it is really true or sort of true for them. Every item score ranged from 1 to 4 , with a higher score indicating perceptions of greater security. Security scores were computed by calculating the mean of responses for all 30 items. 


\section{Sadness Narrative Coding}

The answers to the questions on sad events and coping strategies were coded by trained research assistants into different categories. Inter-rater reliability between the first and the last author's coding was calculated on all responses for both events $(\mathrm{k}=.951)$ and coping strategies $(\mathrm{k}=.906)$ demonstrating strong agreement. Disagreements were conferenced.

Events Children's answers to the question, Let's think about a time recently when you felt very sad and all of the little details you can remember about it. Would you like to describe it in writing? were coded as (a) Coronavirus related events, (b) Parental discord, (c) Imagination (memories of movies or fantasies evoking sad events), (d) Obligations (to do things that are annoying for the children), (e) Peer conflict (which includes bullying and rejection), (f) Mourning and illness, (g) Small accidents, and (h) Reproaches from parents or teachers.

Coping Strategies Children's answers to the question, What did you do to make yourselffeel less sad? were coded following the classification of Kerns et al. (2007) and Eisenberg et al. (1996), using a bottom-up approach: (a) Problem-solving (e.g. taking action to resolve the situation); (b) Playing; (c) Seeking help; (d) Expressing emotion (e.g. crying), (e) Modulating emotion (e.g. taking deep breaths); (f) Using cognitive distraction (thinking about something else); (g) Wishful thinking (imagining a happy end); (h) Receiving help passively; (i) Taking no action. Three scores were derived: (a) Active/constructive coping (including Problem-solving, Playing, Seeking help, Expressing emotion, and Modulating emotion); (b) Disengagement coping (i.e., distraction and wishful thinking); and (c) Inaction (Help passively received, Taking no action). Following QuiñonesCamacho and Davis (2019), children could answer the questions about strategies by saying they did not do anything or that they did not remember, which were coded as describing zero regulatory strategies.

\section{Statistical Analyses}

Mean differences in attachment security were examined among children based on their sad memories, coping responses, and success in overcoming their sadness, using analyses of covariance (ANCOVA) with Bonferroni tests and controlling for children's age and gender. A two-step cluster analysis was conducted to classify children depending on the types of sad memories, coping strategies, and success in overcoming. Dissimilarity was measured by log-likelihood with a predetermined maximum number of 6 clusters. The best cluster solution was chosen based on an average silhouette measure of cohesion and separation greater than
0.2 and the lowest value of the Schwarz'Bayesian Criterion (BIC) with a reasonably large Ratio of BIC Changes and a large Ratio of Distance Measures across the different cluster classifications. Chi-square tests of independence and adjusted standardized residuals were used to examine how the types of sad memories and associated coping strategies and success in overcoming significantly differed across clusters. Finally, mean differences in attachment security were examined across clusters using ANCOVAs controlling for age and gender. For the cluster analysis, we only included participants who had no missing values on sad memories, coping strategies, and success in overcoming ( $N=191,85 \%$ of the total sample). No significant differences were found between complete and incomplete cases on gender, $\chi^{2}(1, N=226)=3.48, p=.062$, age, $F(1$, $224)=0.04, p=.846$, and not missing responses on sad memories, $\chi^{2}(7, N=219)=1.46, p=.984$, coping strategies, $\chi^{2}(2, N=196)=0.45, p=.799$, level of overcoming, $\chi^{2}(1, N=219)=0.20, p=.659$, and attachment security, $F$ $(1,183)=2.28, p=.133$. Listwise deletion was used when examining mean differences in attachment security resulting in a loss of $17 \%$ of the total sample. Again, no significant differences were found between complete and incomplete cases on gender, $\chi^{2}(1, N=191)=1.63, p=.202$, age, $F(1$, $189)=0.45, p=.504$, sad memories, $\chi^{2}(7, N=191)=7.58$, $p=.371$, coping strategies, $\chi^{2}(2, N=191)=0.56, p=.754$, and levels of overcoming, $\chi^{2}(1, N=191)=0.14, p=.705$. Analyses were performed using SPSS 21.

\section{Results}

When children were asked to talk about a sad memory, mourning episodes were the most common episodes evoked, followed by events related to parental discord, peer conflict, small accidents, obligations, reproaches from parents and teachers, coronavirus, and imagination (Table 1). The majority of children (61.6\%) reported constructive coping strategies, whereas disengagement coping strategies were the least common (14.6\%). Finally, the majority of children reported that they overcame the sad event $(84.4 \%)$.

In Table 1, we analyse attachment security differences among children based on the types of sad memories, coping strategies, and the success in overcoming such memories using gender and age as covariates. Results from ANCOVAs showed that children evoking coronavirus-related events, using constructive coping strategies, and reporting to have overcome such sad events had higher levels of attachment security compared to children evoking mourning events, using inaction as a coping strategy, and reporting not overcoming the sad events. 
Table 1 Attachment Security Differences among Children based on Sad Events and associated Coping Strategies, and Overcoming

\begin{tabular}{llll}
\hline & & \multicolumn{2}{l}{ Attachment security } \\
\cline { 4 - 5 } & $N(\%)$ & $M(S D)$ & $F$ \\
\hline Sad events & & & \\
$\quad$ Coronavirus & $12(6.7 \%)$ & $52.32(1.74)_{\mathrm{a}}$ & $2.45^{*}$ \\
Parental discord & $31(17.3 \%)$ & $45.25(1.09)$ & \\
Imagination & $8(4.5 \%)$ & $43.44(2.14)$ & \\
Obligations & $15(8.4 \%)$ & $44.89(1.56)$ & \\
Peer conflict & $28(15.6 \%)$ & $47.48(1.15)$ & \\
Mourning \& separations & $53(29.6 \%)$ & $44.70(0.84)_{\mathrm{a}}$ & \\
Small accidents & $19(10.6 \%)$ & $48.20(1.41)$ & \\
Parents and teachers' & $13(7.3 \%)$ & $46.18(1.71)$ & \\
$\quad$ reproaches & & & \\
Coping strategies & & & \\
Constructive coping & $101(61.6 \%)$ & $47.37(0.62)_{\mathrm{b}}$ & $4.98^{* *}$ \\
Disengagement coping & $24(14.6 \%)$ & $44.45(1.28)$ & \\
Inaction & $39(23.8 \%)$ & $44.03(1.01)_{\mathrm{b}}$ & \\
Overcoming & & & \\
Overcoming & $152(84.4 \%)$ & $46.67(050)_{\mathrm{c}}$ & $10.07^{* *}$ \\
No overcoming & $28(15.6 \%)$ & $42.66(1.16)_{\mathrm{c}}$ & \\
\hline
\end{tabular}

** $p<.01 ; * p<.05$. The values followed by the same letter are significantly different using Bonferroni post hoc pairwise comparisons. Analyses are adjusted for children's age and gender

\section{Cluster Groups}

Two-step cluster analysis was computed to identify groups based on evoked sad memories, coping strategies, and success in overcoming. As shown in Table 2, the BIC value for the four-cluster model showed a better fit than a three-cluster model. The four-cluster solution also had the highest value in the Average Distance Ratio when compared to the other solutions and a total Silhouette mean dissimilarity value of 0.4 indicating a fair quality classification. Table 3 shows the characteristics of the four clusters. Children in cluster 1 , who were more likely to respond with constructive coping strategies and to overcome the episode, had the highest prevalence of events related to coronavirus, parental discord, and small accidents, hence this cluster was named Perceived Successful Constructive Coping - Minor Events. Similar to cluster 1 , children in cluster 2 were likely to respond with constructive coping strategies and to report having overcome the event, but had the highest prevalence of mourning and peer conflict and was therefore named Perceived Successful Constructive Coping - Very Painful Events.

Children in Cluster 3 have resolved their sadness about the described events, but differed from the other clusters because of their use of disengagement or inactivity as coping strategies, hence this cluster was named Perceived Successful Disengagement. Cluster 4 differed from the other clusters mostly because children did not resolve their sadness about the episodes, hence this cluster was named Perceived Unresolved Sadness. About half of the children in this cluster used constructive coping strategies, whereas the other half presented similar percentages of children using disengagement strategies or inaction. Moreover, children in this cluster were more likely to evoke obligation-related events compared to the other clusters.

\section{Attachment Security Differences across Clusters}

Results from ANCOVA testing showed significant differences across the four clusters in security attachment, $F$ (3, $153)=4.51, p=.005$. However, the covariates gender, $F(1$, $153)=2.17, p=.143$, and age, $F(1,153)=0.32, p=.574$, were not significantly associated with security of attachment. Mean differences across clusters are shown in Table 4. Bonferroni post hoc analyses revealed that children in the Perceived Successful Constructive Coping - minor events cluster had significantly higher attachment security compared to children in the Perceived Successful Disengagement and Perceived Unresolved Sadness clusters, which did not significantly differ from each other.

\section{Discussion}

This study used a bottom-up approach to explore how children with different attachment security levels address events perceived as sad. Consistently with our purposes, cluster
Table 2 Evaluation of the Quality of the Classification obtained through Two-step Cluster Analysis

\begin{tabular}{lllll}
\hline Number of Clusters & $\begin{array}{l}\text { Bayesian Information } \\
\text { Criterion (BIC) }\end{array}$ & BIC Changes & $\begin{array}{l}\text { Ratio of BIC } \\
\text { Changes }\end{array}$ & $\begin{array}{l}\text { Ratio of } \\
\text { Distance } \\
\text { Measures }\end{array}$ \\
\hline 1 Cluster & 1302.01 & & & \\
2 Clusters & 1138.13 & -163.88 & 1.00 & 1.41 \\
3 Clusters & 1037.44 & -100.69 & 0.61 & 1.08 \\
4 Clusters & 947.41 & -90.03 & 0.54 & 1.63 \\
5 Clusters & 912.34 & -34.07 & 0.21 & 1.07 \\
6 Clusters & 883.03 & -29.31 & 0.18 & 1.24 \\
\hline
\end{tabular}


Table 3 Cluster Compositions

Cluster 1

(29.8\%)

Perceived Successful Constructive Coping - Minor

Events
Cluster 2

(25.1\%)

Perceived Successful Constructive Perceived Success-

Coping - Very Painful Events
Cluster 3

(30.4\%)

ful Disengagement
Cluster 4

(14.7\%)

Perceived

Unresolved

Sadness

\begin{tabular}{|c|c|c|c|}
\hline \multicolumn{4}{|l|}{ Sad memories } \\
\hline Coronavirus related events & \multicolumn{3}{|c|}{$19.3 \% *$} \\
\hline Parental discord & \multicolumn{3}{|c|}{$26.3 \% *$} \\
\hline Imagination & \multicolumn{3}{|c|}{$5.3 \%$} \\
\hline Obligations & \multicolumn{3}{|l|}{$10.5 \%$} \\
\hline Peer conflict & \multicolumn{3}{|c|}{$0.0 \%$} \\
\hline Mourning \& illness & \multicolumn{3}{|c|}{$0.0 \%$} \\
\hline Small accidents & \multicolumn{3}{|c|}{$28.1 \% *$} \\
\hline Parents or teachers' reproaches & \multicolumn{3}{|c|}{$10.5 \%$} \\
\hline \multicolumn{4}{|l|}{ Coping strategies } \\
\hline Constructive coping & \multicolumn{3}{|c|}{$98.2 \% *$} \\
\hline Disengagement coping & \multicolumn{3}{|c|}{$0.0 \%$} \\
\hline Inaction & \multicolumn{3}{|c|}{$1.8 \%$} \\
\hline \multicolumn{4}{|l|}{ Overcoming } \\
\hline Overcoming & \multicolumn{3}{|c|}{$100.0 \% *$} \\
\hline No overcoming & \multicolumn{3}{|c|}{$0.0 \%$} \\
\hline \multicolumn{4}{|c|}{$\begin{array}{l}* \text { adjusted standardized residuals greater than } 1.96 \text { indicating more ca } \\
\text { strategies: } \chi^{2}(6, N=191)=157.45, p<.001 ; \text { Resolution: } \chi^{2}(3, N=191)\end{array}$} \\
\hline \multicolumn{4}{|c|}{ Table 4 Differences across Clusters in Attachment Security } \\
\hline & \multirow[b]{2}{*}{$N$} & \multicolumn{2}{|c|}{ Attachment security } \\
\hline & & $M(S D)$ & $F$ \\
\hline $\begin{array}{l}\text { 1. Perceived Successful Constructive } \\
\text { Coping - Minor Events }\end{array}$ & 45 & $48.42(0.94)_{a b}$ & $4.51 * *$ \\
\hline $\begin{array}{l}\text { 2. Perceived Successful Constructive } \\
\text { Coping - Very Painful Events }\end{array}$ & 41 & $47.33(0.97)$ & \\
\hline 3. Perceived Successful Disengagement & at 49 & $44.83(0.90)_{\mathrm{b}}$ & \\
\hline 4. Perceived Unresolved Sadness & 24 & $43.49(1.27)_{\mathrm{a}}$ & \\
\hline
\end{tabular}

*** $p<.01$. The values followed by the same letter are significantly different using Bonferroni post hoc pairwise comparisons. Analyses are adjusted for children's age and gender

analysis results showed four distinct clusters characterized by a meaningful variability in the evoked sad events, coping strategies, and ability to solve them. Furthermore, results from ANCOVA testing showed significant differences across the four clusters in the security of the attachment.

In both the first two clusters, children have a similar successful style of coping but differ for the evoked events: whereas in the first cluster, events referred to coronavirus, parental discord, and small accidents, in the second, they referred to particularly painful events such as mourning and peer conflicts. Children in Cluster 3 used disengagement as a coping strategy, whereas children in Cluster 4 did not report to have overcome the sad episodes at all. In both Clusters 1 and 2, children had higher scores of security than in Clusters 3 and 4, even if only the first cluster significantly differed from clusters 3 and 4 . Consistently with the study by Deichmann and Ahnert (2021), children in a secure attachment relationship tended to experience frustration for a shorter time compared to children in an insecure attachment relationship. Indeed, the children with high levels of secure attachment would be significantly more likely to fall into the first cluster than in Clusters 3 and 4. Thanks to the experience of the caregivers' sensitive regulation, children in a secure attachment relationship develop an autonomous ability for emotional self-regulation, becoming self-confident, active in coping with difficulties, and trustful in caregivers' support, more so than insecurely attached children (see Cooke et al., 2019; Zimmer-Gembeck et al., 2017). These results are consistent with those of Contreras et al. (2000), Kerns et al. (2007), and Psouni and Apetroaia (2014) about the association between secure attachment and the use of constructive coping strategies.

Nevertheless, in the present study, the bottom-up approach allows for the identification of children's spontaneous coping strategies and the cluster analysis allows for the individuation of specific patterns of coping strategies associated with attachment security. Indeed, in our study, the different experiences of sadness between the first and the second cluster are differently related to attachment security: 
Children's security in the first cluster could be more related to easier experiences than children in the second cluster, who were undoubtedly more challenged by more serious events. The difficulties for overcoming sadness are greater in the second than in the first cluster, but the children in cluster two succeeded in overcoming remarkable sources of sadness. It could be speculated that in cluster one, children's security of attachment is related to their ability to successfully cope with minor sad events, whereas children's security in cluster two is grounded on an earned ability to cope with very painful events. Some analogies could be identified with the distinction formulated by Main et al. (2003) between continuous and earned security; the first referring to speakers who describe easy attachment experiences; the latter referring to speakers who were coherent despite apparently unfavourable backgrounds (see also Roisman et al., 2014). The analysis of the differences in the successful coping of minor events compared to very painful events among securely attached children could be the subject of future studies.

Cluster 3 and 4 are significantly lower in attachment security, but whereas children in Cluster 3 have overcome the evoked sad events, using disengagement or using no active strategies, children in Cluster 4 did not perceive to have overcome the sad episodes, hence this cluster was named Perceived Unresolved Sadness. Thus, children with low levels of attachment security would be more likely to respond with disengagement or no reaction (Cluster 3 ) or to evoke unresolved sad events (Cluster 4). Regarding Cluster 3, the study of Ştefan et al. (2017) is in line with these findings, showing that the insecure-avoidant pre-schoolers were significantly less likely than securely attached ones to generate constructive strategies. In absence of caregivers' sensitive regulation, insecurely attached children show difficulty in emotional self-regulation and active coping based on the confidence in themselves and their caregivers' support (see the comprehensive review of Brumariu, 2015). As a result, to cope with their sadness, they minimize, suppress, or deny their negative feelings (Main, 1990; Ehrlich et al., 2016).

Conversely, children in Cluster 4 (with the significantly lowest score for security) perceived not having had overcome their sad memories. It could be speculated that their absence of sadness resolution implies some emotional dysregulation, typical either of the attachment anxiety or the attachment disorganization. Indeed, anxious resistant children have the attitude to maximize and heighten their distress to capture the attention of attachment figures (Ainsworth, 1991), whereas disorganized attached children are characterized by the rupture of the processes of emotion regulation (Brenning et al., 2012). Consequently, a limitation of this study is the use of a dimensional measure of attachment which does not allow for discrimination between specific attachment patterns. Future studies could use categorical measures of attachment to discern if the coping strategies would be related not only to the intensity of security but also to specific patterns of insecurity. Using a categorical classification could explore if the insecurely attached children in Cluster 3 could be labelled in the category of avoidance, whereas children in Cluster 4 could be identified either as anxious-resistant or disorganized children. Furthermore, another limitation of our study is the number of participants: a larger sample could obtain results with a greater statistic power and even more specific individuation of the clusters. Finally, information about children's family status could have provided a better understanding of the role of caregivers in influencing children's responses to sad events.

Nevertheless, this study contributes to creating a new field of research on investigating specifically strategies for coping with sad events in middle childhood and their association with attachment security. The study of sadness in children may be particularly useful for clinicians and educators for both understanding the processing of negative emotions such as sadness, and suggesting strategies for sadness management among children which are specific and suitable for their cognitive and emotional development (Zeman et al., 2001).

Author Contributorship Edoardo Saija conceptualized and designed the study, drafted, reviewed and revised the paper. Salvatore Ioverno conducted statistical analyses. Susanna Pallini coordinated the study, contributed to the interpretation of the data, drafted the paper, and reviewed and revised the paper. Roberto Baiocco reviewed the paper for important intellectual content, reviewed and revised the paper. All authors read and approved the final manuscript.

Funding For Salvatore Ioverno, part of the administrative support for this research was provided by the Research Foundation - Flanders (Fonds voor Wetenschappelijk Onderzoek; FWO), [grant number $12 \mathrm{~V} 8120 \mathrm{~N}]$.

Data Availability The datasets generated during and/or analysed during the current study are available from the corresponding author on reasonable request.

\section{Declarations}

Ethics Approval The study was approved by the Ethical Committee of Roma Tre University. The study was conducted in compliance with Ethical principles for medical research involving human subjects of Helsinki Declaration.

Consent to Participate Written informed consent was obtained from the parents. Verbal informed consent was obtained prior to the interview from the participants.

Conflicts of Interest/Competing Interests On behalf of all authors, the corresponding author states that there is no conflict of interest.

\section{References}

Abraham, M. M., \& Kerns, K. A. (2013). Positive and negative emotions and coping as mediators of mother-child attachment and peer 
relationships. Merrill-Palmer Quarterly, 59(4), 399-425. https:// doi.org/10.13110/merrpalmquar1982.59.4.0399

Ainsworth, M. D. S. (1991). Attachment and other affectional bonds across the life cycle. In C. M. Parkes, J. Stevenson-Hinde, \& P. Marris (Eds.), Attachment across the life cycle (pp. 33-51). Routledge.

Bowlby, J. (1988). A secure base. Routledge.

Brenning, K. M., Soenens, B., Braet, C., \& Bosmans, G. U. Y. (2012). Attachment and depressive symptoms in middle childhood and early adolescence: Testing the validity of the emotion regulation model of attachment. Personal Relationships, 19(3), 445-464. https://doi.org/10.1111/j.1475-6811.2011.01372.x

Brumariu, L. E. (2015). Parent-child attachment and emotion regulation. New Directions for Child and Adolescent Development, 2015(148), 31-45.

Carver, C. S., Scheier, M. F., \& Weintraub, J. K. (1989). Assessing coping strategies: A theoretically based approach. Journal of Personality and Social Psychology, 56, 267-283. https://doi.org/10. 1037/0022-3514.56.2.267

Cassidy, J. (1994). Emotion regulation: Influences of attachment relationships. Monographs of the Society for Research in Child Development, 59(2-3), 228-249. https://doi.org/10.1111/j.1540-5834. 1994.tb01287.x

Chalmers, K., Frydenberg, E., \& Deans, J. (2011). An exploration into the coping strategies of preschoolers: Implications for professional practice. Children Australia, 36(3), 120-127.

Compas, B. E., Jaser, S. S., Bettis, A. H., Watson, K. H., Gruhn, M. A., Dunbar, J. P., Williams, E., \& Thigpen, J. C. (2017). Coping, emotion regulation, and psychopathology in childhood and adolescence: A meta-analysis and narrative review. Psychological Bulletin, 143(9), 939-991. https://doi.org/10.1037/bul0000110

Contreras, J. M., \& Kerns, K. A. (2000). Emotion regulation processes: Explaining links between parent-child attachment and peer relationships. In K. A. Kerns, J. M. Contreras, \& A. M. Neal-Barnett (Eds.), Family and peers: Linking two social worlds (pp. 1-26). Praeger.

Contreras, J. M., Kerns, K. A., Weimer, B. L., Gentzler, A. L., \& Tomich, P. L. (2000). Emotion regulation as a mediator of associations between mother-child attachment and peer relationships in middle childhood. Journal of Family Psychology, 14(1), 111-124. https:// doi.org/10.1037/0893-3200.14.1.111

Cooke, J. E., Kochendorfer, L. B., Stuart-Parrigon, K. L., Koehn, A. J., \& Kerns, K. A. (2019). Parent-child attachment and children's experience and regulation of emotion: A meta-analytic review. Emotion, 19(6), 1103-1126. https://doi.org/10.1037/emo0000504.

Deichmann, F., \& Ahnert, L. (2021). The terrible twos: How children cope with frustration and tantrums and the effect of maternal and paternal behaviors. Infancy, 26(3), 469-493. https://doi.org/10. 1111/infa.12389

Ehrlich, K. B., Miller, G. E., \& Jones, J. D. (2016). Attachment and psychoneuroimmunology In Cassidy J \& Shaver PR (Eds.), Handbook of attachment: Theory, research, and clinical applications (pp. 180-201). New York: Guilford Press. [Google Scholar].

Eisenberg, N., Fabes, R. A., Karbon, M., \& Murphy, B. C. (1996). The relations of children's dispositional prosocial behavior to emotionality, regulation, and social functioning. Child Development, 67(3), 974-992. https://doi.org/10.2307/1131874

Han, Z. R., \& Shaffer, A. (2013). The relation of parental emotion dysregulation to children's psychopathology symptoms: The moderating role of child emotion dysregulation. Child Psychiatry \& Human Development, 44(5), 591-601. https://doi.org/10.1007/ s10578-012-0353-7

Harter, S. (1982). The perceived competence scale for children. Child Development, 53(1), 87-97. https://doi.org/10.2307/1129640

Kerns, K. A., Klepac, L., \& Cole, A. (1996). Peer relationships and preadolescents' perceptions of security in the child-mother relationship. Developmental Psychology, 32(3), 457. https://doi. org/10.1037/0012-1649.32.3.457

Kerns, K. A., Abraham, M. M., Schlegelmilch, A., \& Morgan, T. A. (2007). Mother-child attachment in later middle childhood: Assessment approaches and associations with mood and emotion regulation. Attachment \& Human Development, 9(1), 33-53. https://doi.org/10.1080/14616730601151441

Laible, D., \& Thompson, R. A. (2007). Early socialization: A relationship perspective. In J. E. Grusec \& P. D. Hastings (Eds.), Handbook of Docialization: Theory and research (pp. 181207). Guilford Press.

Lazarus, R. S., \& Folkman, S. (1984). Stress, appraisal, and coping. Springer Publishing Company. https://doi.org/10.4135/97814 12952576.n198

Lomas, T. (2018). The quiet virtues of sadness: A selective theoretical and interpretative appreciation of its potential contribution to wellbeing. New Ideas in Psychology, 49, 18-26. https://doi. org/10.1016/j.newideapsych.2018.01.002

Main, M. (1990). Cross-cultural studies of attachment organization: Recent studies, changing methodologies, and the concept of conditional strategies. Human Development, 33(1), 48-61.

Main, M., Goldwyn, R., \& Hesse, E. (2003). Adult attachment classification system version 7.2.Unpublished manuscript, University of California, Berkeley.

Marsac, M. L., Donlon, K. A., Hildenbrand, A. K., Winston, F. K., \& Kassam-Adams, N. (2014). Understanding recovery in children following traffic-related injuries: Exploring acute traumatic stress reactions, child coping, and coping assistance. Clinical Child Psychology and Psychiatry, 19(2), 233-243. https://doi. org/10.1177/1359104513487000

Meherali, S., Punjani, N., Louie-Poon, S., Abdul Rahim, K., Das, J. K., Salam, R. A., \& Lassi, Z. S. (2021). Mental health of children and adolescents amidst CoViD-19 and past pandemics: A rapid systematic review. International Journal of Environmental Research and Public Health, 18(7), 3432. https://doi.org/10. 3390/ijerph18073432

Orgilés, M., Morales, A., Delvecchio, E., Francisco, R., Mazzeschi, C., Pedro, M., \& Espada, J. P. (2021). Coping behaviors and psychological disturbances in youth affected by the COVID-19 health crisis. Frontiers in Psychology, 12, 1-9. https://doi.org/ 10.3389/fpsyg. 2021.565657

Pallini, S., Morelli, M., Chirumbolo, A., Baiocco, R., Laghi, F., \& Eisenberg, N. (2019). Attachment and attention problems: A meta-analysis. Clinical Psychology Review, 74, 101772. https:// doi.org/10.1016/j.cpr.2019.101772

Polan, H. J., \& Hofer, M. A. (2016). Psychobiological origins of infant attachment and its role in development. In J. Cassidy \& P. R. Shaver (Eds.), Handbook of attachment: Theory, research, and clinical applications (3rd ed., pp. 117-132). Guilford Press.

Psouni, E., \& Apetroaia, A. (2014). Measuring scripted attachmentrelated knowledge in middle childhood: The Secure Base script test. Attachment \& Human Development, 16(1), 22-41. https:// doi.org/10.1080/14616734.2013.804329

Quiñones-Camacho, L. E., \& Davis, E. L. (2019). Emotion regulation strategy knowledge moderates the link between cumulative stress and anxiety symptoms in childhood. International Journal of Behavioral Development, 43(4), 369-374. https://doi.org/10. $1177 / 0165025419833821$

Quiñones-Camacho, L. E., \& Davis, E. L. (2020). Children's awareness of the context-appropriate nature of emotion regulation strategies across emotions. Cognition and Emotion, 34(5), 977-985. https:// doi.org/10.1080/02699931.2019.1687426

Roisman, G. I., Haltigan, J. D., Haydon, K. C., \& Booth-LaForce, C. (2014). Earned-security in retrospect: Depressive symptoms, family stress, and maternal and paternal sensitivity from early 
childhood to mid-adolescence. Monographs of the Society for Research in Child Development, 79(3), 85-107.

Skinner, E. A., \& Wellborn, J. G. (1994). Coping during childhood and adolescence: A motivational perspective. Life-Span Development and Behavior, 12, 91-133. https://doi.org/10.1007/978-1-47572677-0_14

Song, J. H., Colasante, T., \& Malti, T. (2018). Helping yourself helps others: Linking children's emotion regulation to prosocial behavior through sympathy and trust. Emotion, 18(4), 518-527. https:// doi.org/10.1037/emo0000332

Ştefan, C. A., Avram, J., \& Miclea, M. (2017). Children's awareness concerning emotion regulation strategies: Effects of attachment status. Social Development, 26(4), 694-708. https://doi.org/10. 1111/sode. 12234

Steyn, M., \& Moen, M. (2019). Drawing sadness: What are young children telling us? Early Child Development and Care, 189(1), 79-93. https://doi.org/10.1080/03004430.2017.1301936

Thompson, R. A. (1994). Emotion regulation: A theme in search of definition. Monographs of the Society for Research in Child Development, 59(2-3), 25-52. https://doi.org/10.1111/j.15405834.1994.tb01276.x

Waters, E., \& Cummings, E. M. (2000). A secure base from which to explore close relationships. Child Development, 71(1), 164-172.

Waters, S. F., \& Thompson, R. A. (2014). Children's perceptions of the effectiveness of strategies for regulating anger and sadness. International Journal of Behavioral Development, 38(2), 174181. https://doi.org/10.1177/0165025413515410

Webb, T. L., Miles, E., \& Sheeran, P. (2012). Dealing with feeling: A meta-analysis of the effectiveness of strategies derived from the process model of emotion regulation. Psychological Bulletin, 138(4), 775-808. https://doi.org/10.1037/a0027600
Yunger, J. L., Corby, B. C., \& Perry, D. G. (2005). Dimensions of attachment in middle childhood. In Kerns and Richardson (2005) Kerns, K. A., \& Richardson, R. A. (Eds.). (2005). Attachment in Middle Childhood. Guilford press.

Zeman, J., \& Garber, J. (1996). Display rules for anger, sadness, and pain: It depends on who is watching. Child Development, 67(3), 957-973. https://doi.org/10.1111/j.1467-8624.1996.tb01776.x

Zeman, J., \& Shipman, K. (1997). Social-contextual influences on expectancies for managing anger and sadness: The transition from middle childhood to adolescence. Developmental Psychology, 33(6), 917-924. https://doi.org/10.1037/0012-1649.33.6.917

Zeman, J., Shipman, K., \& Penza-Clyve, S. (2001). Development and initial validation of the children's sadness management scale. Journal of Nonverbal Behavior, 25(3), 187-205. https://doi.org/ 10.1023/A:1010623226626

Zimmer-Gembeck, M. J., Skinner, E. A., Morris, H., \& Thomas, R. (2013). Anticipated coping with interpersonal stressors: Links with the emotional reactions of sadness, anger, and fear. The Journal of Early Adolescence, 33(5), 684-709. https://doi.org/ $10.1177 / 0272431612466175$

Zimmer-Gembeck, M. J., Webb, H. J., Pepping, C. A., Swan, K., Merlo, O., Skinner, E. A., Avdagic, E., \& Dunbar, M. (2017). Is parentchild attachment a correlate of children's emotion regulation and coping? International Journal of Behavioral Development, 41(1), 74-93. https://doi.org/10.1177/0165025415618276

Publisher's Note Springer Nature remains neutral with regard to jurisdictional claims in published maps and institutional affiliations. 